\title{
Developing a Comprehensive, Assessment-based Continuous Improvement Process for a Library Instruction Program
}

\section{Sarah Lucchesi, Michigan Technological University}

Sarah Lucchesi has a BA in Biological Sciences from Wellesley College, an MA in Science Education from Boston University, and an MLS from Simmons College. She has been working at Michigan Technological University since August 2012 with a focus on information literacy instruction, assessment, and patents.

\section{Jennifer Sams, Michigan Technological University}

Jennifer Sams received both her BA in English with a concentration in Secondary Education and her MS in Library and Information Science from the University of Illinois. She started at Michigan Technological University in the Fall of 2012 as an Instruction \& Learning Librarian.

\section{Ms. Lauren Movlai, Michigan Technological University}

Lauren Movlai has BAs in Psychology and English from University of the Pacific, and an MLS from University of Denver. She is an instruction and learning librarian at Michigan Technological University with a focus on information literacy instruction.

\section{Erin S Matas, Michigan Technological University}

Erin Matas holds an MSI from the University of Michigan. She is the Faculty Engagement and Research Support Librarian at Michigan Technological University and leads the library's Student Research Consultants, a group of students who provide peer-to-peer library research help.

\section{Nora Allred, Michigan Technological University}

Nora Allred is Scholarly Communications and Copyright Librarian at the J. Robert Van Pelt and Opie Library at Michigan Technological University. She provides copyright and fair use awareness to the campus community through the library's webpage, presentations, instruction sessions, and one-on-one consultations. As Co-PI on the NSF ethics education project, she lead the learning module on copyright and fair use for graduate students. 


\title{
Developing a Comprehensive, Assessment-based Continuous Improvement Process for a Library Instruction Program
}

\begin{abstract}
The library education team at Michigan Technological University, an engineering-focused university, is developing a multifaceted process for assessment of our information literacy instruction program in order to continuously improve our teaching and related activities. The majority of library instruction sessions are 50-minute, one-shot classes with little or no follow-up from the faculty or students involved; as such, the efficacy of library instruction programs can be difficult to measure. In addition to already existing rubric-based information literacy assessments of student work, the education team is establishing a suite of accompanying methods for gathering both quantitative and qualitative data about our instructional activities. In summer 2015, the team participated in a retreat at which a number of methods of data collection were proposed. Four areas were selected for further development. A formal method for soliciting faculty feedback via a post-instruction survey has already been deployed and will collect responses throughout the fall 2015 and spring 2016 semesters. Three additional data collection methods will be launched in January 2016: a peer observation system, a rubric-based selfassessment, and analysis of student work products generated in the library instruction sessions. Collectively, these feedback mechanisms provide actionable information about the teaching effectiveness of individual librarians as well as the effectiveness of our education program as a whole. Information gathered from these assessment processes will be used in a variety of ways, including individual goal-setting for the following academic year, changing lesson plans to more closely align with students' needs and abilities, and generating specific and concrete recommendations for improving teaching and pedagogy for each instruction librarian. This paper reports on the process of developing each of these data collection methods, the information that has been gathered, and how that information has been applied to the improvement of our library instruction program.
\end{abstract}

\section{Background/Rationale}

The library education team at Michigan Technological University, a mid-sized, STEM-focused university, has grown steadily over the past six years to a team of three librarians dedicated to instruction plus an additional two who provide course-integrated instruction in times of high demand and workshops in their areas of expertise. In the 2014-2015 academic year, the education team conducted 174 instruction sessions, reaching 3,959 students, faculty, staff, and community members. Along with this growth, we have developed assessment processes that allow us to evaluate students' information literacy skills by examining their work products (such as research papers, annotated bibliographies, and background research reports) with a rubric. This assessment process serves two purposes: it allows us to determine whether the information literacy skills we teach in course-integrated instruction sessions are the skills our students actually need the most practice with, and it also contributes to the university-wide assessment of information literacy as a designated undergraduate student learning goal. However, such rubric assessments only allow us to evaluate our work in course-integrated information literacy sessions in which students produce an easily assessable product. We also conduct workshops open to 
anyone, as well as department-specific literature review preparation sessions for graduate students, and many undergraduate course-integrated instruction sessions in which students are producing work that does not lend itself well to formal rubric assessment. To better assess our overall suite of instructional offerings, additional assessment methods were needed.

While we have made significant progress in assessing our teaching effectiveness via rubric assessment of our students' products, prior to the project described in this paper we had not conducted any assessment of our own skills as content developers, lesson planners, and teachers. In order to develop a more holistic narrative of the effectiveness of our education program, assessing ourselves, our peers, as well as our students, is crucial. While rubric assessment of student work products benefits our course-integrated sessions, assessment of ourselves as teachers benefits the overall instruction program through improving skills and proficiencies that can be applied across all types of instruction.

\section{Literature Review}

The implementation of a continuous improvement plan ensures that a library instruction program meets the needs of students, librarians, and faculty. While many academic libraries have adopted a range of assessment methods and tools to apply to student work in order to ensure that graduates have critical information literacy skills, it is also necessary to close the loop with a plan for improving and updating instruction ${ }^{1}$.

Continuous improvement plans can take a range of forms in library instruction, including preand post-tests or evaluations, student surveys, evaluation of student work, self reflection, peer or supervisor evaluation, and pedagogical workshops ${ }^{2,3,4,5,6}$. Libraries that have implemented continuous improvement plans have found that librarians become more engaged with their work as they share knowledge gained with each other ${ }^{7}$, students find library instruction sessions more useful $^{8}$, and both the quality of librarian teaching and the depth of student research skills increases ${ }^{9}$. Based on this, and on the preferences and strengths of our librarians, we chose to develop a continuous improvement plan that uses data from the following tools: peer observation, analysis of student work, faculty feedback, and self-evaluation. A benefit of conducting four forms of assessment, as we did, is that each one provides a well-rounded understanding of the strengths and weaknesses of our current instruction.

Both within academic libraries and more broadly at the university level, peer observation has increasingly been used as a tool to gauge teaching effectiveness, solicit feedback from colleagues, and trade pedagogical knowledge between library instructors ${ }^{10,11,12,13,14}$. When developing an effective system for peer observation, there are a wide range of common tools, such as Richter scales, checklists, guided discussion questions, and free-form conversations, that librarians can develop or modify ${ }^{2,3,15}$. While there are benefits and drawbacks to each tool, one of the major overarching challenges of the peer observation process is librarians' reluctance to be evaluated or assessed by colleagues. Contributing to this are feelings of uneasiness in judging or being judged by a peer, actual or perceived risks in evaluating a co-worker of a different rank, the time required, and a lack of pedagogical training in library school ${ }^{4,11}$. Numerous other implementations of peer observations in library instruction have demonstrated the importance of emphasizing that assessment should be seen as a learning process and an opportunity for improvement for the instructor and the observer ${ }^{11,15,16,17}$. Colleagues are able to best assess their 
peers' subject knowledge, quality of materials and examples used, and how library research skills are applied to the students' course and assignments ${ }^{10}$. Observers benefit from seeing new applications of ideas and pedagogical techniques they may not have previously considered for their own instruction ${ }^{4}$.

Collecting in-session data from students provides a way for librarians to learn what students understood from an instruction session. Many librarians may measure the success or failure of an instruction session by the number of questions students asked, but an analysis of student work products can provide a more measurable, concrete, and accurate picture of student understanding. Examples of work products and student data that could be collected are one minute papers ${ }^{18}$, student surveys ${ }^{4}$, responses to questions asked during the session ${ }^{8}$, and student worksheets ${ }^{19}$. Although students are not experts in the field, they can offer feedback on confusing jargon, the speed of the session, and aspects of the content they didn't understand ${ }^{4}$. Additionally, planning library instruction sessions that result in a tangible product produced by the student may benefit their learning by involving them more actively in the lesson through the work they complete ${ }^{4}$.

Self-assessment can take numerous forms including journaling or making a portfolio. Improvements to future sessions can spring from reflection about successes and areas for improvement in a given class. Self-reflection can help librarians develop their pedagogical skills, reflect on successes and failures, and help them develop a longitudinal record of what worked and what didn't during an instruction session ${ }^{4}$.

The final form of assessment in our plan is faculty feedback. Faculty can be asked for feedback formally through a survey or informally through a discussion. Topics that librarians may want to solicit feedback on include: the content and activities in the session, the relevance of the session to the class and assignments, student learning from the session, the pedagogical skills of the librarian, or suggestions for improving the session ${ }^{15}$. Faculty-librarian communication can result in the design of more relevant activities and lessons from the librarians ${ }^{6}$. It can also result in faculty gaining a better understanding of what information literacy is and what library instruction sessions entail, while librarians can get a sense of faculty attitudes towards library instruction sessions. Since the faculty are experts in their field, they can provide unique suggestions and comments on the instruction sessions provided.

The compilation of multiple methods of data collection into a holistic continuous improvement plan will allow us to improve and tailor our instruction to better serve our campus.

\section{Program Development Process}

In August of 2015, the education team organized and attended a retreat dedicated to improving and planning for library instruction over the coming academic year. While we had informally considered methods of continuous improvement in the past, at this meeting we set aside dedicated brainstorming time to develop a plan. To prepare for this activity, all librarians read Gewirtz's Evaluating an Instruction Program With Various Assessment Measures ${ }^{4}$ and glanced over an ACRL self-assessment tool called Proficiencies for Instruction Librarians ${ }^{20}$. 
During the brainstorming meeting, each librarian was asked to independently list all of the types of information or data that could potentially be collected and assessed as part of the library instruction process. Some examples of data included: worksheets used in a session, surveys sent to students or faculty, final projects or papers, informal conversations, lesson plan feedback from colleagues, our own observation of student engagement during sessions, attendance at workshops, changes in reference interactions after instruction, and resource usage. Each individual idea was placed on a sticky note and sorted under an appropriate population (students, faculty, community members, and ourselves) where we might collect that data. After all ideas were sorted, a discussion ensued on how to group the types of potential data and what our team would find most useful in a continuous improvement process. We settled on the following methods to explore:

- Self-assessment tools

- Face-to-face faculty feedback

- Peer observation system

- Lesson plan workshopping/pedagogical sessions

- In-session data from students

After further discussion, we elected to have pairs of librarians collaborate to develop a program, tool, or system for each topic. Several days after the retreat, we transferred the topics into a survey and each librarian ranked their top three choices of projects to work on. Based on their choices, librarians were paired up and assigned topics. Each of the five librarians was able to work on two projects and no two pairs were the same. This allowed for a diversity of ideas and a workload that was balanced based on interest.

After projects were assigned, pairs worked independently to develop a plan for their topic, with the understanding that we would begin implementation by the spring semester at the latest for all of the projects. As the projects evolved, some of the methods were modified to better meet logistical concerns. Rather than face-to-face faculty feedback, the librarian pairing working on this decided to develop a form to ensure that feedback data was recorded and accessible. The librarians focused on lesson plan workshopping and pedagogical sessions determined that approaching these as an informal discussion group based around topics that arose from the other methods would work best for our team. Thus, further development of this piece was paused until the other methods could be implemented. We met as a full group twice over the fall semester to touch base, update one another, ask questions, and provide additional ideas.

\section{Assessment Methods}

\section{Peer Observation}

As instructors, each of the librarians on the education team has a range of strengths. In order to take advantage of this and learn from one another, we developed a peer observation plan. We deliberately did not develop a peer evaluation system because our ultimate goal is to provide one another with concrete ideas for improvement and change, not simply a summative judgement on teaching skills. This encourages reflection on teaching practices for both the observer and instructor. 
As part of this plan, each librarian is asked to observe and be observed once per semester. Pairings are determined based on availability and areas of interest. For example, if a librarian is interested in the flipped classroom technique, she might observe a librarian who uses it regularly. In addition to an observation, this process includes a pre- and post- meeting between the pair that is guided by an observation form.

We elected to use open-ended discussion questions for both meetings and the observation form to allow for natural dialogue and the exploration of topics that interest both observer and instructor. The forms will not be collected or housed centrally with anyone; the librarians involved are individually responsible for completing them and using them in conjunction with the other continuous improvement methods, such as self-assessment, to develop their skills.

The pre-observation meeting and form should be completed 2-7 days prior to an observation. The library instructor must provide a brief overview of the session and its learning goals. The form also asks the observer to describe what skills, techniques, or teaching methods she would like to learn from observing her colleague teach, and asks the instructor what specifically she would like feedback on. We provided several suggested areas to observe that align with our department's vision including engagement/management of students, demonstrations and examples, adaptability, active learning techniques, use of technology, and demeanor. See Appendix A for the form and written observation instructions.

During the observation, we explicitly requested that observers take any notes directly on a paper copy of the form instead of on a laptop. We wanted to minimize the feeling that colleagues were being judged and preserve an atmosphere of comfort and open learning. The observers are asked to note strengths of the instructor, areas of improvement, and new ideas learned.

The post-observation meeting and form should be completed 1-7 days after the session, to ensure that feedback is provided while the instruction is fresh in both parties' minds. Post-observation, participants should discuss notes taken during the observation and action steps for both the observer and the library instructor. Both parties leave the experience with concrete, actionable next steps. This was a critical consideration in the development of both the peer observation process and the form.

\section{Student Work Analysis}

Analysis of student work products will focus specifically on work produced and collected during a library session. Collection of in-session data will vary dramatically by course and session. Different student levels, learning outcomes across sessions, course topics, and in-class activities can dictate what type of work is produced and therefore collected during a session. One example of an in-session activity is included in Appendix B. Librarians also have the option to collect formative or summative work; assessing formative work could be incredibly valuable in pinpointing where in the middle of a process students are struggling, while summative work at the end of a session could provide information on students' comfort with library resources and ability to transfer what they have practiced. For the first iteration of this method, we will conduct these assessments by targeting one course each semester. 
For this method, assessment will be informal. Due to the variations in the information collected, we cannot have a standard rubric or assessment tool for all work products; however, we have developed a basic understanding of the elements we should be looking at in order to gauge student learning and formulate a plan for improvement. Within most work, librarians can look at keyword and synonym selection to see if students understand the concept, examine the complexity of the search strategies students develop, and judge their skills in evaluating and determining source relevance.

The results of these assessments will help us refine our instruction methods to modify future sessions for improved instruction and student learning.

\section{Self-Assessment}

The rubric-based self-assessment is designed to be the most individual, personal, and flexible system of the four data collection methods. The rubric, which uses the ACRL Proficiencies for Instruction Librarians ${ }^{21}$ as the criteria, offers a wide variety of self-assessment categories. Because many of the proficiencies for instruction librarians are not applicable to every member of the education team, each librarian has modified the rubric to apply to their specific set of responsibilities. In consultation with their supervisor, each librarian will decide how they will conduct their self-assessment using their own personally modified version of the rubric. These self-selected categories and topics will help inform professional development as librarians are able to identify concrete skills for improvement.

This self-assessment method offers flexibility in goal setting by allowing individual librarians to design their own improvement plans. Self-assessments are conducted during the spring semester so that librarians have the summer to reflect on which skills identified for improvement they would like to focus on, and to develop a goal and action plan. The performance goal cycle begins in the fall semester, so librarians spend the academic year following the self-assessment working on their improvement plans and re-assess the following spring. Librarians choose whether goals identified through rubric topics are supervised and formal with action plans for improvement, or informal and self-led. If paired with a peer observation session in which the observer focuses on the skill under development, the librarian can benefit from another perspective on their chosen area of improvement. Further, mentors or peers who excel at a particular skill that is in development could be identified through this process. The self-assessment rubric can be used to organize goal setting into two tiers: short-term (6 months or 1 semester) and long-term (annual), or identify short-term goals that support an ongoing or long-term goal. Professional development opportunities such as webinars, conference sessions, or reading articles on a topic are easily targeted once areas for improvement are identified. Journaling or note taking immediately after each instruction session with the chosen area(s) for improvement in mind could offer valuable insights on goal progress.

The self-assessment rubric is an important component of our continuous improvement processes because it allows librarians to reflect on and develop their instructional skills privately, without the anxiety than can result from observation or perceived judgement. Librarians will discuss one or two identified areas for improvement from their self-assessment rubric with their supervisor or may elect to keep their full rubric assessment private and self-led, without supervision. During 
the development process, librarians considered it essential to have this opportunity for individual improvement in addition to the group-based methods.

\section{Faculty Feedback}

Faculty and instructors whose courses visit the library for instruction are a valuable source of assessment information for the library education team. Prior to fall 2015, we developed a brief online survey (Appendix C) that is sent to instructors immediately following their course's library instruction session. Instructors rate how strongly they agree with the following statements:

- The library information session met the needs of my students

- I anticipate that the information covered in the library session will help my students find quality sources for their research-related projects

- The pedagogical techniques used during the session were effective and appropriate to the information covered.

The education team discussed whether to leave the form anonymous or require that the instructor fill out the course number (and thus give us a way to correlate responses with instructor). Ultimately, it was decided not to make the form anonymous since the feedback we get from the form is much more useful if we know which course it pertains to. Each instruction session is customized to the needs and level of the given course, so it is essential to be able to correlate whether the instructor judged that pedagogical techniques and activities used in those sessions were effective.

\section{Application of Results}

The team is at various stages of implementation with each of the four assessment methods under development and has already gathered valuable information that can be used to improve our lesson planning and pedagogical practices. A few illustrative examples are described below.

The peer observation system was intentionally structured to be helpful for both the instructing librarian and the observing librarian, with the knowledge that everyone has strengths that observers can learn from. The first round of peer observations yielded helpful and constructive feedback for the instructors, and observers left with new ideas for their own lesson plans. One librarian found that "[ $t]$ he peer observation process has given me more confidence in my teaching and has sparked a culture of collaboration within our department." Another librarian remarked that, from the perspective of the teacher being observed, another set of eyes in the classroom was valuable because "sometimes it is hard to observe everything when you are caught up in the moment of teaching." An instructor may not always notice when a student in the middle of the room looks confused, while a neutral observer can take in more of these details.

Observers noted new uses of the library's instructional technology they had not previously considered, as well as strengths of the instructors, such as providing good context for the lesson's activities, that will be deliberately incorporated into future lesson plans. For instructors, it was helpful to have an outside perspective on clarity of instructions, inflection, and tone. Post- 
observation conversations also prompted in-depth discussions of resources used in a given discipline and how to approach upper-level versus first year students.

The first round of self-assessment has proven to be particularly illuminative for librarians. One participant reflected on the value of thoughtfully examining her skills and abilities, noting that 'having 'expertise' in a subject is a double-edge sword. I know my content and can keep it current. But in knowing a topic well there is a danger of complacency. What is a seemingly simple concept to me may be challenging to my audience. Jargon becomes so familiar it becomes my standard vocabulary. The instructor/learner dynamic becomes strained." Self-assessment paired with peer observation allowed her to see herself as an expert through her students' eyes, where that very valued expertise could be daunting. Another librarian began a system of reflective journaling after instruction sessions based on the areas she identified for improvement in the self-assessment rubric. She observes that "self-reflection and journaling after instruction sessions was an unfamiliar and daunting concept and one that I have found surprisingly helpful. Comparing my notes with the rubric proficiencies has been an informative exercise that adds grounding and confidence to my teaching. I have been able to use the rubric to first evaluate my proficiencies and then follow my progress." We feel that keeping the self-assessment portion of the continuous improvement process personal, flexible, and open-ended has allowed each librarian to use it to her own maximum benefit, by allowing for individual variation in how people prefer to reflect and process thoughts.

Feedback from faculty has been positive and, most importantly for the education team, specific enough to be useful in planning future sessions. Faculty have indicated that more time is needed for explaining the peer review process and interlibrary loan, conveying the value for students to learn how to evaluate an anonymous source, and that even their students who had written review papers before still learned something new. Comments such as these from instructors are not typically revealed in face-to-face conversations after the instruction session, so having this source of information allows us to refine lesson plans for future semesters more effectively.

One instructor commented that it would be very helpful for students to return to the library in a subsequent class session and conduct research for their own topics with the help of the librarian and instructor. We were able to contact that instructor to tell them that we do offer that service and asked them to schedule a time for their students to come back to the library for a research session. We also often assume that students beyond the first year level know what peer review is and how this knowledge can be applied in a literature search. Feedback from faculty, combined with observational data from instruction sessions, has led us to incorporate more peer review information in upper level courses as well as first year sessions.

\section{Next Steps and Scalability}

One of the major benefits to this continuous improvement plan has been its adaptability and flexibility. Because the development and implementation processes were driven by the needs and interests of the librarians involved, our continuous improvement plan is free to change as our needs evolve. It also lends itself well to implementation at other institutions, despite potential variations in size and population. 
Student work analysis and collection provides one of our largest areas for change and improvement. Time, technology, and number of librarians can impact the process of collecting student work both in our library and in any library that may want to adapt the methods we have implemented. While the work we have been able to collect thus far has provided valuable information, we intend to expand this piece of the continuous improvement plan through the introduction of student surveys in order to gather data on student's thoughts and feelings regarding library instruction. We would also like to move toward a more intentional method of collecting student work to ensure that a wide range of work products, generated by a variety of students, can be assessed. This is particularly critical as our student population skews heavily towards engineering and other STEM majors, and we would like to ensure that the breadth of samples we collect reflects this. Additionally, the goals and needs brought to light via the other continuous improvement tools may guide the ways in which our student work analysis changes over time.

At the end of the academic year, we will evaluate the effectiveness of the ACRL Proficiencies for Instruction Librarians rubric ${ }^{20}$ for our education team. Given that this is such an individualized piece of our program, with each librarian modifying the rubric independently, we will not likely make any significant changes to the tool as group, just in how we use it. This broad appeal makes the self-assessment rubric particularly beneficial to another institution that might be interested in continuous improvement, as it can be adapted very simply to emphasize the goals and strategic plan of a particular library. That said, after the first cycle of self-assessment, we are planning to incorporate some method or tool to close the loop, and ensure that knowledge gained from the tool is put to use. While we have not yet determined what this will look like, we know it will need to be flexible based on the improvement methods chosen, and completed in consultation with the librarian's supervisor. If used consistently, the self-assessment rubric will provide us with an opportunity to examine changes in focus and personal improvement in instruction over time.

While the peer observation piece of the program was also intentionally designed to be broad, there are already a number of adjustments planned for it based on feedback from librarians. Rather than using the same form for the observer and library instructor, we intend to create separate forms for each role. Among other changes, the new instructor forms will include a section for thoughts on what the instructor felt went well or could be improved during a session. Observer forms will include a question that prompts a discussion about any elements of the lesson or instruction that the instructor does not want to have observed. We found that some librarians were already aware of specific issues in their instruction and were working to improve them. Receiving feedback on these issues did not always add to the conversation and detracted from areas the observer wanted to learn about or the library instructor wanted to focus on.

Additionally, while we are not currently planning to scale up the peer observation portion, we recognize that it could easily be done both within our own library and by larger institutions by adding additional observations. Scaling it down to meet the needs of a smaller library with fewer instruction librarians or a departmental librarian who only teaches in a given discipline would potentially pose a greater challenge. In both scenarios, or even in a larger library, librarians could investigate a collaboration with the campus teaching and learning support systems or a faculty member with a strong interest in teaching, thus creating an avenue for new partnerships in addition to continuous improvement. 
Like the peer observation data, we plan to use the faculty feedback to improve and adjust upcoming instruction sessions. This will be done both on a personal level and a program level, depending on the specific types of feedback. The form itself worked very well this past semester, and at the moment there are no plans to change it. We found that sending the form to faculty immediately after the session and keeping the questions brief, directed, and close-ended resulted in useful feedback and was appreciated by the recipients. Like the other tools developed in this plan, it is extremely flexible should someone wish to adhere to these guidelines but adapt it for another institution.

All of these data collection methods will be used as a springboard to begin the development of one final continuous improvement method. The librarians on our education team have expressed interest in meeting regularly with the explicit goals of discussing educational trends, pedagogy, classroom strategies, and more. We are planning to host at least one instruction team luncheon devoted entirely to discussion of one of these topics each semester. Already from the data we have, we know that several librarians would like to spend one of these lunches focused on techniques for getting an instruction session back on track after being de-railed by technology or other significant issues. We anticipate that other topics will arise as more data is collected.

Not only is continuous improvement an ongoing process, we have found that the development of a continuous improvement plan must also be ongoing. After one semester, our plan has begun to provide numerous avenues for improvement of our program, while also highlighting the strengths and weakness of the tools we have developed.

\section{References}

1. Maki, P.L. "Developing an Assessment Plan to Learn about Student Learning." Journal of Academic Librarianship 28, no. 1-2 (2002): 8-13.

2. Golparian, S., J. Chan, and A. Cassidy. "Peer Review of Teaching: Sharing Best Practices." Collected Essays in Learning and Teaching, 8 (2015): 211-217.

3. Gonzalez, A.J. "Needs Assessment of Library Instruction at Texas A\&M University Libraries Using Student Feedback." Performance Measurement and Metrics 10, no. 2 (2009): 122-133.

4. Gewirtz, S.R. "Evaluating an Instruction Program With Various Assessment Measures." Reference Services Review 42, no. 1 (2014): 16-33.

5. Oakleaf, M. "Dangers and Opportunities: A Conceptual Map of Information Literacy Assessment Approaches." Portal: Libraries \& The Academy 8, no. 3 (2008): 233-253.

6. Belanger, J., R. Bliquez, and S. Mondal. "Developing a Collaborative Faculty-Librarian Information Literacy Assessment Project." Library Review 6, no. 3 (2012): 68-91.

7. Chim, W. "The Quest for Excellence: One Library’s Experience." Library Management 28, no. 6/7 (2007): 323-336.

8. Dunaway, M.K., and M.T. Orblych. "Formative Assessment: Transforming Information Literacy Instruction." Reference Services Review 39, no. 1 (2011): 24-41.

9. Oakleaf, M. “The Information Literacy Instruction Assessment Cycle: A Guide for Increasing Student Learning and Improving Librarian Instructional Skills" Journal of Documentation 65, no. 4 (2009): 539-560.

10. Middleton, C. "Evolution of Peer Evaluation of Library Instruction at Oregon State University Libraries." Portal: Libraries \& The Academy 2, no. 1 (2002): 69-78.

11. Alabi, J., and W.H. Weare. "Peer Review of Teaching." Communications in Information Literacy 8, no. 2 (2014): 180-191.

12. Keig, L., and M.D. Waggoner. "Collaborative Peer Review: The Role of Faculty in Improving College 
Teaching." ASHE-ERIC Higher Education Report Series 23, no. 2 (1994).

13. Cosh, J. "Peer Observation in Higher Education--A Reflective Approach."

Innovations in Education and Training International 35, no. 2 (1998): 171-176.

14. Orsmond, P. "Peer Observation of Teaching." The New Academic 6, no. 2 (1993).

15. Snavely, L., and N. Dewald. "Developing and Implementing Peer Review of Academic Librarians' Teaching: An Overview and Case Report.” Journal Of Academic Librarianship 37, no. 4 (2011): 343-351.

16. Alabi, J., R. Huisman, M. Lacy, W. Miller, E. Snajdr, J. Trinoskey, and W.H. Weare Jr. "By and For Us: The Development of a Program for Peer Review of Teaching By and For Pre-tenure Librarians." Collaborative Librarianship 4, no. 4 (2012): 165-174.

17. Samson, S., and D.E. McCrea. "Using Peer Review to Foster Good Teaching." Reference Services Review 36, no. 1 (2008): 61-70.

18. Chionski, E., and M. Emanuel. "The One-Minute Paper and the One-Hour Class: Outcomes Assessment for One-Shot Library Instruction." Reference Services Review 34, no. 1 (2006): 148-155.

19. Watson, S.E., C. Rex, J. Markgraf, H. Kishel, E. Jennings, and K. Hinnant. "Revising the 'One-Shot' Through Lesson Study: Collaborating with Writing Faculty to Rebuild a Library Instruction Session" College \& Research Libraries 74, no. 4 (2013): 381-398.

20. Association of College \& Research Libraries. "Standards for Proficiencies for Instruction Librarians and Coordinators." Association of College \& Research Libraries. Last modified June 2007.

http://www.ala.org/acrl/standards/profstandards. 
Appendix A: Peer Observation Form

\section{Peer Observation Form}

Instructor:

Observer:

This form is intended to be a guideline for both the observer and the instructor to use.

\section{Pre-conference}

Date:

Session Overview:

Session Goals:

Possible areas to observe:

- Engagement/ Management of students

- Demonstrations/ examples

- Adaptability

- Active learning techniques

- Use of technology

- Demeanor

Observer would like to learn:

Instructor would like feedback on: 


\section{Observation}

Date:

As you are taking notes, please keep in mind the specific areas that the instructor would like you to focus on.

Strengths of the instructor:

Areas of Improvement:

New ideas/ new things learned:

Additional notes: 


\section{Post-Observation Conference}

Date:

Action steps for observer:

Action steps for instructor: 
Appendix B: Worksheet For In-Session Student Work

\section{Segment 1: Determine Information Need (10 minutes)}

Overview: In this segment, you will read a case study and determine what information you would need to research in this scenario, and then generate a list of search terms.

Scenario:

In 2011, KNB EFX Group and QuickSilver Controls were asked to develop a robotic dolphin to be used in filming a movie, particularly in scenes that would be too dangerous or time consuming with a live dolphin. The scenes with the robotic dolphin were to be filmed in saltwater aquarium tanks with human actors and other live dolphins in the water with the robot.

The requirement that the robot be fully operable under salt water necessitated some changes to the materials that might typically be used in robot construction. As the lead project engineer, you must ensure that the robotic dolphin will function in the saltwater aquarium tank without polluting it. There is a tight timetable for filming, so you have to get it right the first time! Before you begin designing your robot, what research do you need to do?

Step 1: In the box below, list all of the information you will need to find. Add as many bullet points as you need, one for each piece of the research puzzle you need to put together. (limit to $5-6$ items in the interest of time)

E.g. Research safe, non-toxic alternatives to oils and chemicals typically used in robotics. 
For the rest of the activity, you will be working with the research question "What materials are used to make robots for use in seawater?"

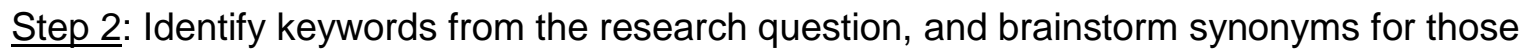
keywords.

- Example: For the research question "What designs maximize the hydrodynamic efficiency of submersibles?" your table of keywords and synonyms might look like this:

\begin{tabular}{|l|l|l|}
\hline \multicolumn{1}{|c|}{ Keyword } & \multicolumn{1}{|c|}{ Synonym 1 } & \multicolumn{1}{c|}{ Synonym 2 } \\
\hline submersibles & "underwater craft" & "underwater robot" \\
\hline hydrodynamic & "water flow" & streamlined \\
\hline efficiency & productivity & performance \\
\hline design & form & plan \\
\hline
\end{tabular}

Use the table below to create your own list of keywords and synonyms for the research question "What materials are used to make robots for use in seawater?" Synonyms can also be broader or narrower terms (i.e. "truck" is a narrower term than "vehicle").

\begin{tabular}{|l|l|l|}
\hline Keyword & Synonym 1 & Synonym 2 \\
\hline & & \\
\hline & & \\
\hline & & \\
\hline & & \\
\hline
\end{tabular}




\section{Segment 2: Devise Search Strategy (10 minutes)}

Overview: In this segment, you will generate a search strategy and try it out in a database.

Step 1: Use your table of keywords and synonyms to build a search strategy.

Example: using the example keywords/synonyms table above, one search strategy might be: - hydrodynamic* AND efficien* AND (submersible OR "underwater robot")

${ }^{* *} T^{*}{ }^{* *}$

- Use AND, OR, and NOT (also known as "Boolean Operators") to link your concepts.

- Use an asterisk (*) to cut off words if you want to search for all words with that root. For example, "develop*" would search for develop, developing, developed, development, developmental, etc.

- Put quotes around a phrase that you want the database to search as a phrase, rather than as individual words.

Use this space to record your search strategy:

Step 2: From the "Finding Articles" tab on the course guide, open the database called ProQuest Engineering. In ProQuest, click on the link for Advanced Search.

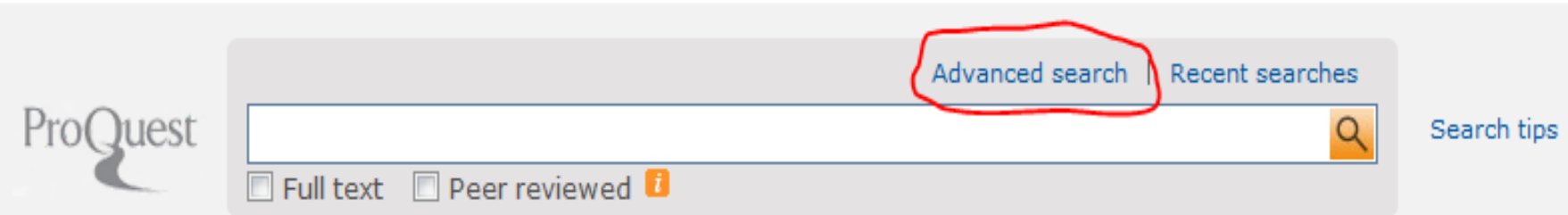

Step 3: Enter your search strategy in the advanced search window and click "Search." 
Step 4: Take a moment to scroll through the search results and evaluate their quality and relevance. Think about the following things:

- How many results are there? In your opinion, is this too many, too few, or just right?

- How many of the results relate to the research question? Only a few? About half? Most?

- Do most of the results leave out some part of the research question? For example, are the results about robots in general, not specifically underwater robots?

Use the box below to record your evaluation of the search results. Bullet points are fine. 


\section{Segment 3: Revise Search \& Select Source (10 minutes)}

Overview: In this segment, you will revise your search strategy and choose one useful looking article from the search results and then evaluate its relevance.

Step 1: Look again at your search results and evaluation of them. Make a few changes to the search strategy that you think will lead to improved results.

Use this space to record your revised search strategy:

Step 2: Go back to the advanced search page and enter your revised search strategy. Reevaluate the list of results. Are they better than last time? Worse? How so?

Use the box below to record your evaluation of the new search results. Bullet points are fine.

Step 3: As a group, select one journal article you think is very relevant to the research question. How can you get to the full text of this article? Link to full text right in database or using HuskyFetch? If using HuskyFetch, can you find it online, in print, or through Interlibrary Loan? 
Step 4: Say why you think this article is relevant to the research question. Bullet points are fine.

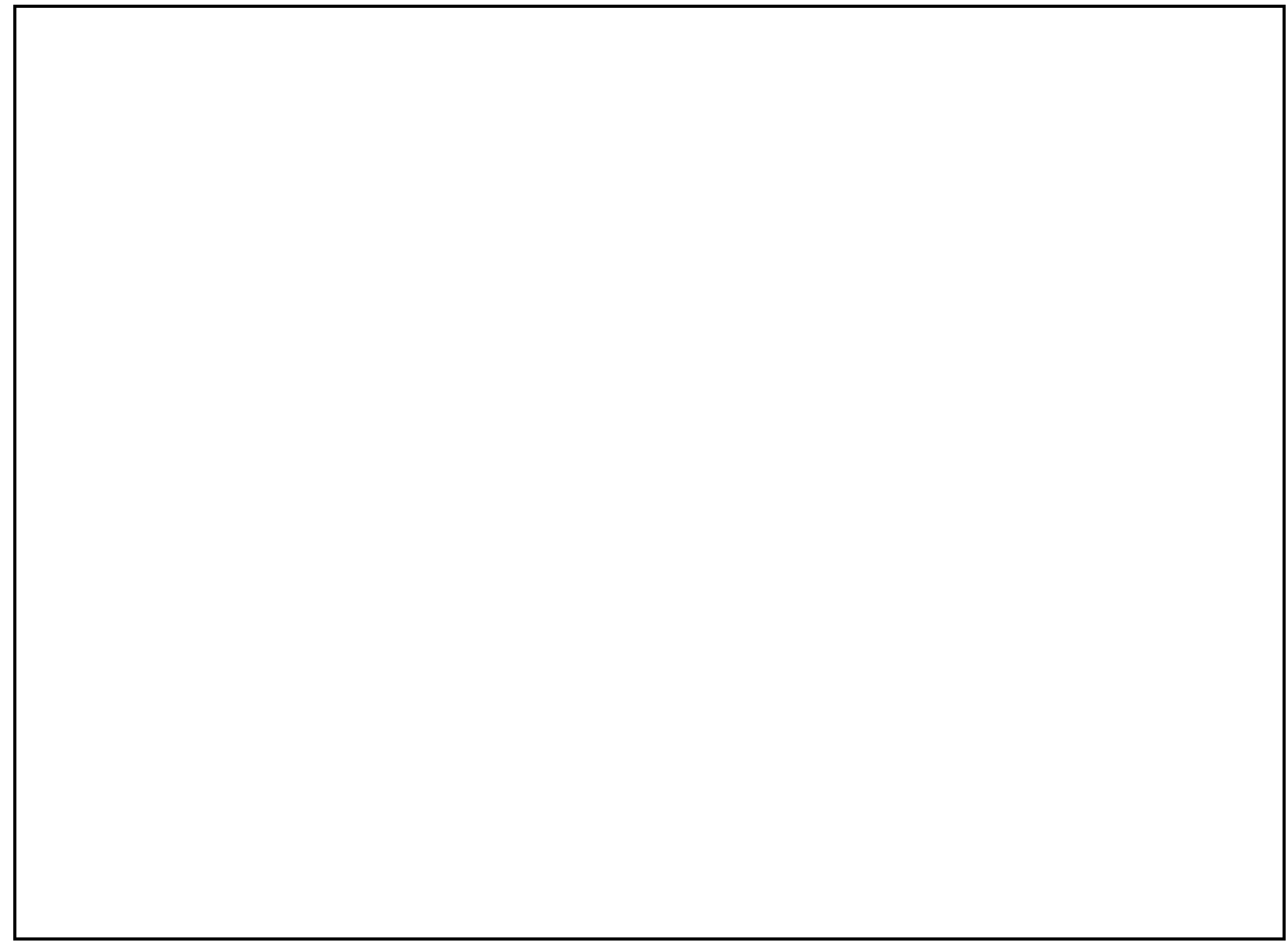


Appendix C: Faculty Feedback Form

\section{Post-Library Instruction Survey - Faculty}

Thank you so much for taking the time to fill out our library instruction survey! We appreciate your honest feedback. Questions with a red asterisk are required, the rest are optional.

* Required

Course Number *

(e.g. $\operatorname{CS} 3110)$

Your answer

Section (if applicable)

Your answer

The library session met the information needs of my students

Strongly disagree

D Disagree

O Agree

Strongly agree 
I anticipate that the information covered in the library session will help my students find quality sources for their researchrelated projects.
Strongly disagree
$\bigcirc$ Disagree
$\bigcirc$ Agree
Strongly agree

The pedagogical techniques used during the session were effective and appropriate to the information covered.
$\bigcirc$ Strongly disagree
$\bigcirc$ Disagree
$\bigcirc$ Agree
Strongly agree

Other comments and feedback: 